\title{
POLA MOBILITAS PENDUDUK NON-PERMANEN PADA DAERAH AKSESIBILITAS RENDAH DI KECAMATAN SIJUNJUNG KABUPATEN SIJUNJUNG
}

\author{
Fierza Inestasia \\ Program Studi Geografi Fakultas Ilmu Sosial, \\ Universitas Negeri Padang Email : \\ fierzaines@gmail.com
}

\begin{abstract}
ABSTRAK
Penelitian ini bertujuan untuk memperoleh data dan gambaran mengenai pola mobilitas penduduk non-permanen pada daerah aksesiblitas rendah di Kecamatan Sijunjung dilihat dari : 1) Karakteristik pelaku, 2) Arah tujuan, 3) Alasan mobilitas , 4) Pola mobilitas.

Jenis penelitian ini menggunakan metode deskriptif kuantitatif. Populasi penelitian ini rumahtangga di Nagari Silokek, Nagari Durian Gadang, Nagari Aie Angek, Nagari Solok Ambah, dan Nagari Paru, dengan menggunakan rumus slovin mendapatkan jumlah sampel responden 97 rumahtangga. Dengan teknik analisa data menggunakan rumus persentase.

Hasil penelitian meliputi : 1) Terdapat 95 orang dari 97 rumahtangga yang melakukan mobilitas non-permanen, dominan berstatus sebagai anak berjumlah 54 orang $(57 \%)$.

Karakteristiknya dominan laki-laki berjumlah 58 orang (61\%), dominan berumur $18-28$ tahun berjumlah 35 orang (37\%). Pendidikan terakhir dominan tamat SMP berjumlah 22 orang (23\%). Pekerjaan dominan sebagai pelajar/mahasiswa berjumlah 32 orang (34\%). Pendapatan dominan tidak memiliki pendapatan berjumlah 32 orang (34\%). 2) Arah dominan melewati batas kecamatan berjumlah 49 orang (51\%). 3) Alasan dominan karena pekerjaan berjumlah 63 orang (66\%). 4) Pola mobilitas dominan menginap berjumlah 61 orang (64\%). Kata Kunci : Mobilitas Penduduk Non-Permanen, Aksesibilitas
\end{abstract}

\section{ABSTRACT}

This study aims to obtain data and description of the pattern of mobility of non-permanent residents in low accessibility areas in Sijunjung District seen from: 1) Characteristics of actors, 2) Destination direction, 3) Reasons for mobility, 4) Mobility pattern.

This research uses quantitative descriptive method. The population of this study were households in Nagari Silokek, Nagari Durian Gadang, Nagari Aie Angek, Nagari Solok Ambah, and Nagari Lung, using the slovin formula obtained sample of 97 household respondents. With data analysis technique using percentage formula.

The results of the study included: 1) There were 95 people from 97 households who performed non-permanent mobility, dominant status as children amounted to 54 people (57\%). Characteristics of male dominant amounted to 58 people $(61 \%)$, dominantly aged $18-28$ years amounted to 35 people (37\%). The last education dominantly graduated from junior high school was 22 people (23\%). The dominant work as a student is 32 people (34\%). The dominant income has no income of 32 people (34\%). 2) The dominant direction over the kecamatan border is 49 people (51\%). 3) The dominant reason for the work was 63 people (66\%). 4) The dominant mobility pattern of stay was 61 people (64\%).

Keywords: Mobility of Non-Permanent Residents, Accessibility

\footnotetext{
${ }^{1}$ Mahasiswa Geografi Fakultas Ilmu Sosial Universitas Negeri Padang

2 Dosen Geografi Fakultas Ilmu Sosial Universitas Negeri Padang. Pembimbing I : Dr. Paus Iskarni, M.Pd, Pembimbing II : Dr. Ernawati, M.Si
} 


\section{Pendahuluan}

Manusia sebagai makhluk
sosial senantiasa terus bergerak,
melewati batas sosial maupun
kewilayahan untuk meningkatkan
kemampuan dan kapasitasnya dalam
upaya menuju kesejahteraan serta
untuk memenuhi suatu kebutuhan.
Mulai dari kebutuhan pangan,
sandang, dan papan. Manusia
biasanya akan melakukan sebuah
pergerakan yang biasanya disebut

dengan mobilitas penduduk (Tirtosudarmo dalam Mincie $\mathrm{H}$. Ubro, dkk , 2015).

Mobilitas penduduk atau dapat disebut dengan migrasi nonpermanen merupakan salah satu dari tiga komponen pada pertumbuhan penduduk yang dapat menambah atau mengurangi jumlah penduduk di suatu wilayah (R.H. Hardoko, 1987). Komponen ini bersama dengan kelahiran dan kematian dalam mempengaruhi dinamika penduduk seperti jumlah, komposisi, dan

distribusi keruangan. Manusia melakukan perpindahan penduduk ini terkait juga dengan persoalan kemiskinan dan pengangguran pada suatu wilayah. Hal tersebut merupakan salah satu faktor pendorong dan penarik bagi

penduduk untuk melakukan mobilitas. Penyediaan fasilitas untuk pembangunan wilayah serta kelancaran sarana transportasi antar wilayah untuk peningkatan prasarana jalan diikuti dengan pengadaan kendaraan umum juga menjadi penyebab terjadinya mobilitas atau perpindahan penduduk di suatu wilayah yang tidak menetap dikarenakan beberapa alasan dan tujuan. Namun pada dasarnya prasarana jalan maupun transportasi yang kurang memadai dapat menghambat pelaksanaan mobilitas tersebut. Sehingga frekuensi mobilitas, terutama pada mobilitas non-permanen yang dilakukan masyarakat akan berbeda-beda. (Mantra, 2009:177-178).

Mobilitas non-permanen merupakan mobilitas penduduk yang tidak bersifat menetap, secara umum terbagi atas : a) ulang-alik yaitu penduduk melewati batas teritorial dalam waktu satu hari paling lama atau tidak menginap, batas waktu enam jam atau lebih dan kembali pada hari yang sama. b) menginap yaitu penduduk melewati batas teritorial dalam masa kurang dari enam bulan atau lebih dari enam bulan tetapi tidak untuk menetap.

Pada tiap daerah, penduduk melakukan mobilitas non-permanen untuk memenuhi kebutuhan hidup terkhususnya untuk melakukan pekerjaan maupun untuk menempuh pendidikan. Hal tersebut juga terjadi pada daerah Kabupaten Sijunjung.

Kecamatan Sijunjung merupakan satu dari 8 kecamatan yang ada di Kabupaten Sijunjung dan berada di Ibukota Kabupaten Sijunjung dengan luas wilayah $74.800 \mathrm{Km}^{2}$. Dimana batas-batas wilayah Kecamatan Sijunjung di 
sebelah utara berbatasan dengan Kecamatan Sumpur Kudus \& Provinsi Riau, sebelah Selatan berbatasan dengan Kecamatan Lubuk Tarok \& Kecamatan Tanjung Gadang, sebelah Timur berbatasan dengan Kecamatan Kamang Baru \& Provinsi Riau, dan sebelah Barat berbatasan dengan Kecamatan IV Nagari \& Kecamatan Koto VII. Di

Kecamatan Sijunjung terdapat sembilan nagari yaitu Nagari Muaro, Nagari Sijunjung, Nagari Pematang Panjang, Nagari Kandang Baru, Nagari Aie Angek, Nagari Solok Ambah, Nagari Paru, Nagari Silokek, dan Nagari Durian Gadang. Dari sembilan nagari tersebut ada beberapa nagari yang memiliki aksesibilitas yang rendah dilihat dari jauhnya nagari ke pusat kecamatan, banyak kondisi jalan yang kurang baik (banyak jalan yang amblas) serta frekuensi angkutan yang terbatas. Nagari tersebut diantaranya adalah Nagari Silokek, Nagari Durian Gadang, Nagari Aie Angek, Nagari Solok Ambah dan Nagari Paru.

Kelima nagari tersebut memiliki aksesibilitas rendah dilihat dari segi kondisi jalan yang kurang baik, transportasi yang terbatas dan jarak tempuh ke jalan utama yang jauh. Pada nagari Durian Gadang dan nagari Silokek memiliki kondisi jalan yang kurang baik. Jika dari jalan besar, jalan menuju nagari tersebut di sebelah kanannya ada sungai yang besar dan di sebelah kirinya tebing.
Sedangkan pada nagari Aie Angek, Solok Ambah, dan Paru memiliki jarak menuju pusat kecamatan yang cukup jauh, frekuensi transportasi terbatas, serta kondisi jalan yang kurang baik dan cukup terjal.

$$
\text { Seperti dikutip dari }
$$

Padangkita.com "Pada tanggal 15

Mei 2017 daerah Silokek dan Durian Gadang terjadi longsor hal ini disebabkan tingginya curah hujan sehingga menyebabkan badan jalan sepanjang 80 meter terban masuk sungai. Sehingga transportasi Muaro Sijunjung arah ke Nagari Silokek dan Durian Gadang putus total". Oleh sebab itu proses mobilitas kedua nagari tersebut terganggu.

Secara keseluruhan dari kelima nagari tersebut untuk sarana transportasi kurang adanya angkutan umum bagi masyarakat, hanya ada satu atau dua kali seminggu angkutan umum yang tersedia itupun angkutan umum tersebut hanya mengantarkan masyarakat untuk keluar dari nagari mereka tidak bias mengantarkan mereka keluar dari batas kecamatan juga. Ada pula sebagian masyarakat melakukan mobilitas non-permanen menggunakan kendaraan pribadi namun tidak seluruh masyarakat yang memilikinya. Dengan keadaan aksesibilitas dan transportasi seperti itu mengakibatkan mobilitas penduduk terhambat terutama pada mobilitas non-permanen yang melewati batas kecamatan tersebut.

Oleh karena itu daerah yang memiliki aksesibilitas rendah pada 
tiap nagari akan memiliki perbedaan mobilitas masyarakatnya saat melakukan mobilitas. Baik masyarakat yang melewati batas kecamatan, kabupaten, maupun provinsi karena setiap orang pasti mempunyai alasan tersendiri serta arah yang akan ingin dituju bagi penduduk yang melakukan mobilitas karena pada daerah asal terdapat keterbatasan sarana (pendidikan maupun lapangan pekerjaan).

Maka untuk itu peneliti tertarik untuk melakukan penelitian dengan judul "Pola Mobilitas Penduduk

Non-Permanen Pada Daerah Aksesibilitas Rendah di Kecamatan Sijunjung Kabupaten Sijunjung.

\section{Tujuan Penelitian}

1. Untuk mengetahui karakteristik pendudukdiKecamatan

Sijunjung yang melakukan mobilitas non-permanen dilihat dari segi umur, jenis kelamin, pendidikan, dan pekerjaan di daerah tujuan.
2. Untuk mengetahui arah mobilitas penduduk non-permanen di Kecamatan Sijunjung minimal melewati batas kecamatan.

3. Untuk mengetahui alasan penduduk melakukan mobilitas non-permanen.

4. Untuk mengetahui bagaimana pola mobilitas penduduk nonpermanenpadadaerah aksesibilitas rendah di Kecamatan Sijunjung.

\section{Metode Penelitian}

Jenis penelitian yang digunakan dalam penelitian ini adalah penelitian deskriptif kuantitatif. Penelitian ini dilakukan di lima nagari pada Kecamatan Sijunjung yang memiliki aksesibilitas rendah yaitu : Nagari Silokek, Nagari Durian Gadang, Nagari Aie Angek, Nagari Solok Ambah, dan Nagari Paru.

Peta Lokasi Penelitian dapat dilihat pada gambar 1 :

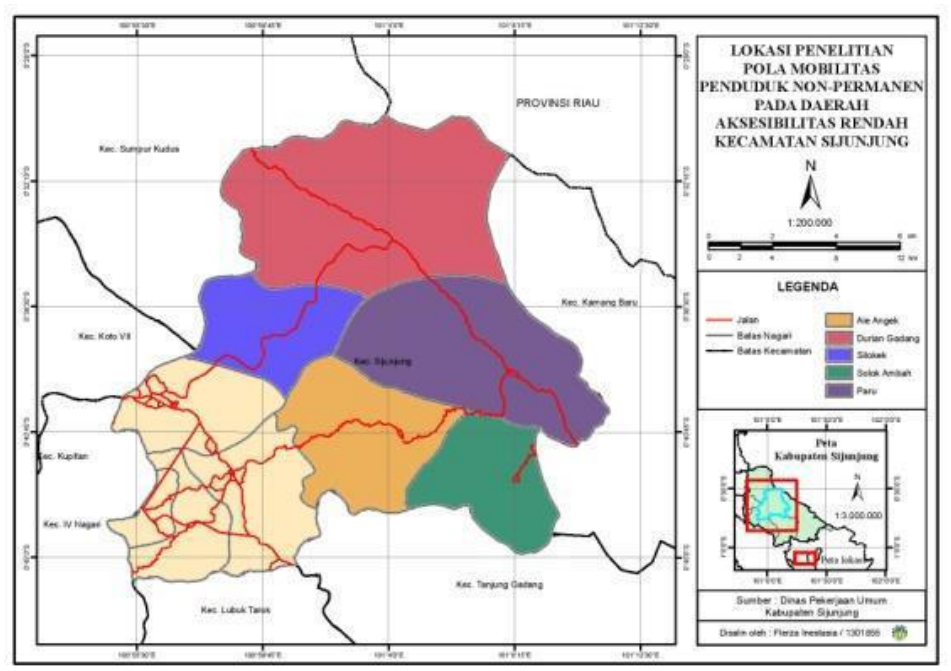

Gambar 1. Peta Lokasi Penelitian 
1. Populasi dan Sampel

$$
\text { Populasi dalam }
$$

penelitian ini adalah seluruh rumah tangga yang ada di

Nagari Silokek, Nagari

Durian Gadang, Nagari Solok

Ambah dan Nagari Paru

minimal salah satu

anggotanya melakukan

mobilitas non-permanen minimal melewati batas

kecamatan.

Teknik pengambilan sampel

dilakukan 2 macam yaitu : a. Sampel

Wilayah

Teknik pengambilan sampel wilayah ini dilakukan secara Stratified Random Sampling berdasarkan aksesibilitas pada masing-masing nagari.

Tabel 1. Tingkat Aksesibilitas Nagari di Kecamatan Sijunjung

\begin{tabular}{|c|c|c|c|c|c|c|c|c|c|c|c|c|c|}
\hline No & Nagari & $\begin{array}{c}\text { Jarak ke Ibu } \\
\text { Kecamatan } \\
(\mathbf{K m})\end{array}$ & Skor & Sarana Angkut & Skor & $\begin{array}{l}\text { Frekuensi } \\
\text { Angkutan }\end{array}$ & Skor & Status Jalan & Skor & $\begin{array}{c}\text { Bahan } \\
\text { Jalan }\end{array}$ & Skor & Total & Ket. \\
\hline 1. & Muaro & 4 & 2 & $\begin{array}{l}\text { Angkutan Desa, } \\
\text { Ojek, Mini Bus }\end{array}$ & 2 & $\begin{array}{l}>10 \times 1 \\
\text { minggu }\end{array}$ & 2 & $\begin{array}{c}\text { Jalan } \\
\text { Kolektor \& } \\
\text { Lokal }\end{array}$ & 4 & Aspal & 2 & 12 & Tinggi \\
\hline 2. & Sijunjung & 0 & 2 & $\begin{array}{l}\text { Angkutan Desa, } \\
\text { Ojek, Mini Bus }\end{array}$ & 2 & $\begin{array}{l}>10 \times 1 \\
\text { minggu }\end{array}$ & 2 & $\begin{array}{c}\text { Jalan Arteri, } \\
\text { Kolektor, dan } \\
\text { Lokal }\end{array}$ & 4 & Aspal & 2 & 12 & Tinggi \\
\hline 3. & $\begin{array}{c}\text { Pematang } \\
\text { Panjang }\end{array}$ & 5 & 2 & $\begin{array}{l}\text { Angkutan Desa, } \\
\text { Ojek, Mini Bus }\end{array}$ & 2 & $\begin{array}{l}>10 \times 1 \\
\text { minggu }\end{array}$ & 2 & $\begin{array}{c}\text { Jalan Arteri, } \\
\text { dan Lokal }\end{array}$ & 4 & Aspal & 2 & 12 & Tinggi \\
\hline 4. & $\begin{array}{c}\text { Kandang } \\
\text { Baru }\end{array}$ & 8 & 2 & $\begin{array}{l}\text { Angkutan Desa, } \\
\text { Ojek, Mini Bus }\end{array}$ & 2 & $\begin{array}{l}>10 \times 1 \\
\text { minggu }\end{array}$ & 2 & $\begin{array}{c}\text { Jalan Arteri } \\
\text { dan Lokal }\end{array}$ & 4 & Aspal & 2 & 12 & Tinggi \\
\hline 5 . & $\begin{array}{c}\text { Solok } \\
\text { Ambah } \\
\end{array}$ & 24 & 1 & $\begin{array}{c}\text { Angkutan Desa, } \\
\text { Ojek }\end{array}$ & 2 & $\begin{array}{l}<10 \times 1 \\
\text { minggu } \\
\end{array}$ & 1 & Jalan Lokal & 1 & $\begin{array}{l}\text { Beton, } \\
\text { Kerikil }\end{array}$ & 1 & 6 & Rendah \\
\hline 6. & Paru & 30 & 1 & Angkutan Desa & 1 & $\begin{array}{c}<10 \mathrm{x} \\
\text { seminggu }\end{array}$ & 1 & Jalan Lokal & 1 & $\begin{array}{l}\text { Aspal, } \\
\text { Beton }\end{array}$ & 1 & 5 & Rendah \\
\hline 7. & Aie Angek & 15 & 1 & $\begin{array}{c}\text { Angkutan Desa, } \\
\text { Ojek }\end{array}$ & 2 & $\begin{array}{c}<10 \mathrm{x} \\
\text { seminggu }\end{array}$ & 1 & Jalan Lokal & 1 & $\begin{array}{l}\text { Aspal, } \\
\text { Beton }\end{array}$ & 1 & 6 & Rendah \\
\hline 8. & Silokek & 18 & 1 & $\begin{array}{c}\text { Angkutan Desa, } \\
\text { Ojek }\end{array}$ & 2 & $\begin{array}{c}<10 \mathrm{x} \\
\text { seminggu }\end{array}$ & 1 & Jalan Lokal & 1 & $\begin{array}{l}\text { Beton, } \\
\text { Kerikil }\end{array}$ & 1 & 6 & Rendah \\
\hline 9. & $\begin{array}{l}\text { Durian } \\
\text { Gadang }\end{array}$ & 23 & 1 & Angkutan Desa & 1 & $\begin{array}{c}<10 \mathrm{x} \\
\text { seminggu }\end{array}$ & 1 & Jalan Lokal & 1 & $\begin{array}{l}\text { Beton, } \\
\text { Kerikil }\end{array}$ & 1 & 5 & Rendah \\
\hline
\end{tabular}

Sumber : Hasil Pengolahan Data Sekunder 2017

Dari tabel 1 di atas terlihat ada lima nagari yang memiliki aksesibilitas rendah dan empat nagari yang memiliki aksesibilitas tinggi. Maka peneliti mengambil lima nagari

\section{b. Sampel Responden}

Dari rumus slovin pada daerah aksesibilitas rendah di Kecamatan Sijunjung terdapat sampel responden 97 RT.

\section{Teknik Analisa Data}

Sesuai dengan tujuan penelitian maka data yang diperoleh diolah dengan menggunakan analisa yang memiliki aksesibilitas rendah sebagai sampel wilayah, yaitu nagari Silokek, nagari Durian Gadang, nagari, Aie Angek, nagari Solok Ambah dan nagari Paru.

deskriptif dengan rumus persentase untuk melihat kecendrungan masingmasing variabel, menggunakan rumus sebagai berikut:

Keterangan :

$\mathrm{P}$ : Persentase

f : Frekuensi jawaban responden

$\mathrm{n}$ : Jumlah Responden 


\section{Hasil dan Pembahasan}

Kecamatan

Sijunjung

merupakan salah satu kecamatan yang ada di Kabupaten Sijunjung.

Secara astronomis Kecamatan Sijunjung terletak pada $100^{\circ} 55$ 09' "BT

- $101^{\circ} 058^{\prime \prime} \mathrm{BT}$ dan $0^{\circ} 1444^{\prime \prime} \mathrm{LS}$ -

$0^{\circ} 44$ '17 LS. Secara geografis

Kecamatan Sijunjung memiliki batas

wilayah : Sebelah utara berbatasan

dengan Provinsi Riau, Sebelah

selatan berbatasan dengan
Kecamatan Tanjung Gadang dan Kecamatan Lubuk Tarab, Sebelah barat berbatasan dengan Kecamatan Sumpur Kudus, Kecamatan Koto VII dan Kecamatan IV Nagari, Sebelah timur berbatasan dengan Kecamatan Kandang Baru.

Berdasarkan data diperoleh di lapangan dari 97 rumah tangga terdapat 95 orang yang melakukan mobilitas non-permanen minimal melewati batas kecamatan.

\section{Karakteristik Pelaku Mobilitas Penduduk Non-Permanen}

1. Jenis Kelamin

Tabel 2. Deskripsi Frekuensi Jenis Kelamin Pelaku Mobilitas Penduduk Non-Permanen Pada Daerah Aksesibilitas Rendah di Kecamatan Sijunjung

\begin{tabular}{|c|c|c|c|c|c|c|c|}
\hline \multirow{2}{*}{ No. } & \multirow{3}{*}{ Daerah Asal } & \multicolumn{4}{|c|}{ Jenis Kelamin } & \multicolumn{2}{|c|}{} \\
\cline { 3 - 8 } & & \multicolumn{2}{|c|}{ Laki-laki } & Perempuan & \multicolumn{2}{c|}{ Jumlah } \\
\cline { 3 - 8 } & & $\mathrm{F}$ & $\%$ & $\mathrm{~F}$ & $\%$ & $\mathrm{f}$ & $\%$ \\
\hline 1. & Silokek & 7 & 12 & 4 & 11 & 11 & 12 \\
\hline 2. & Durian Gadang & 11 & 19 & 9 & 24 & 20 & 21 \\
\hline 3. & Aie Angek & 14 & 24 & 11 & 30 & 25 & 26 \\
\hline 4. & Solok Ambah & 11 & 19 & 8 & 22 & 19 & 20 \\
\hline 5. & Paru & 15 & 26 & 5 & 13 & 20 & 21 \\
\hline & Jumlah & 58 & 100 & 37 & 100 & 95 & 100 \\
\hline
\end{tabular}

Sumber : Pengolahan Data Primer, 2017

Berdasarkan data yang diperoleh dari tabel 3 di atas, pelaku mobilitas penduduk non-permanen pada daerah aksesibilitas rendah di 2.

Umur

Tabel 3. Deskripsi Frekuensi Umur Pelaku Mobilitas Penduduk NonPermanen Pada Daerah Aksesibilitas Rendah di Kecamatan Sijunjung

\begin{tabular}{|c|c|c|c|c|c|c|c|c|c|c|c|c|c|}
\hline \multirow{3}{*}{ No. } & \multirow{3}{*}{ Daerah Asal } & \multicolumn{10}{|c|}{ Umur } & \multirow{2}{*}{\multicolumn{2}{|c|}{ Jumlah }} \\
\hline & & \multicolumn{2}{|c|}{ 7-17 Tahun } & \multicolumn{2}{|c|}{ 18-28 Tahun } & \multicolumn{2}{|c|}{$\begin{array}{l}29-39 \\
\text { Tahun }\end{array}$} & \multicolumn{2}{|c|}{$\begin{array}{l}40-50 \\
\text { Tahun }\end{array}$} & \multicolumn{2}{|c|}{$>50$ Tahun } & & \\
\hline & & $\bar{F}$ & $\%$ & $\mathrm{~F}$ & $\%$ & $\mathrm{f}$ & $\%$ & $\mathrm{~F}$ & $\%$ & $\mathrm{f}$ & $\%$ & $\mathrm{~F}$ & $\%$ \\
\hline 1. & Silokek & 2 & 11 & 4 & 11 & 3 & 12 & 2 & 13 & - & - & 11 & 12 \\
\hline 2. & Durian Gadang & 4 & 21 & 8 & 23 & 6 & 24 & 2 & 13 & - & - & 20 & 21 \\
\hline 3. & Aie Angek & 4 & 21 & 11 & 32 & 5 & 20 & 5 & 34 & - & - & 25 & 26 \\
\hline 4. & Solok Ambah & 4 & 21 & 5 & 14 & 8 & 32 & 2 & 13 & - & - & 19 & 20 \\
\hline 5. & Paru & 5 & 26 & 7 & 20 & 3 & 12 & 4 & 27 & 1 & 100 & 20 & 21 \\
\hline & Jumlah & 19 & 100 & 35 & 100 & 25 & 100 & 15 & 100 & 1 & 100 & 95 & 100 \\
\hline
\end{tabular}

Sumber : Pengolahan Data Primer, 2017
Kecamatan Sijunjung lebih banyak penduduk yang berjenis kelamin laki-laki berjumlah 47 orang $(60 \%)$. 
Berdasarkan data yang diperoleh dari tabel 4 di atas, umur pelaku mobilitas non-permanen pada daerah aksesibilitas rendah di Kecamatan Sijunjung lebih banyak penduduk dengan umur $18-28$ tahun berjumlah 32 orang $(41 \%)$ sedangkan yang sedikit dengan umur $>50$ tahun berjumlah 1 orang $(1 \%)$.

3. Jenis Pekerjaan

Tabel 4. Deskripsi Frekuensi Jenis Pekerjaan Pelaku Mobilitas Penduduk NonPermanen Pada Daerah Aksesibilitas Rendah di Kecamatan Sijunjung

\begin{tabular}{|c|c|c|c|c|c|c|c|c|c|c|c|c|c|c|c|c|c|c|c|c|c|c|c|c|c|}
\hline \multirow{3}{*}{ No. } & \multirow{3}{*}{ Daerah Asal } & \multicolumn{22}{|c|}{ Jenis Pekerjaan } & \multirow{2}{*}{\multicolumn{2}{|c|}{ Jumlah }} \\
\hline & & \multicolumn{2}{|c|}{$\begin{array}{l}\text { Penambang } \\
\text { Emas }\end{array}$} & \multicolumn{2}{|c|}{$\begin{array}{c}\text { Pekerja } \\
\text { Bengkel }\end{array}$} & \multicolumn{2}{|c|}{ Honorer } & \multicolumn{2}{|c|}{$\begin{array}{c}\text { Pegawai } \\
\text { Negeri }\end{array}$} & \multicolumn{2}{|c|}{$\begin{array}{c}\text { Pelajar/ } \\
\text { Mahasiswa }\end{array}$} & \multicolumn{2}{|c|}{ Pedagang } & \multicolumn{2}{|c|}{$\begin{array}{l}\text { Petani/ } \\
\text { Pekebun }\end{array}$} & \multicolumn{2}{|c|}{ Supir } & \multicolumn{2}{|c|}{ Wiraswasta } & \multicolumn{2}{|c|}{$\begin{array}{c}\text { Tukang } \\
\text { Bangunan }\end{array}$} & \multicolumn{2}{|c|}{$\begin{array}{c}\text { Karyawan } \\
\text { Swasta } \\
\end{array}$} & & \\
\hline & & $\mathrm{f}$ & $\%$ & $\mathrm{~F}$ & $\%$ & $\mathrm{~F}$ & $\%$ & $\mathrm{f}$ & $\%$ & $\mathrm{f}$ & $\%$ & $f$ & $\%$ & $\mathrm{~F}$ & $\%$ & $f$ & $\%$ & $f$ & $\%$ & $\mathrm{f}$ & $\%$ & $\mathrm{f}$ & $\%$ & $f$ & $\%$ \\
\hline 1. & Silokek & 2 & 40 & - & - & 1 & 9 & - & - & 3 & 9 & 2 & 15 & 1 & 9 & - & - & - & - & - & - & 2 & 40 & 11 & 12 \\
\hline 2. & $\begin{array}{c}\text { Durian } \\
\text { Gadang }\end{array}$ & 2 & 40 & - & - & 1 & 9 & 1 & 25 & 10 & 31 & 4 & 31 & 2 & 18 & - & - & - & - & - & - & - & - & 20 & 21 \\
\hline 3. & $\begin{array}{c}\text { Aie } \\
\text { Angek }\end{array}$ & 1 & 20 & 2 & 67 & 3 & 27 & - & - & 7 & 22 & 3 & 24 & 2 & 18 & 2 & 50 & 2 & 40 & 1 & 50 & 2 & 40 & 25 & 26 \\
\hline 4. & $\begin{array}{c}\text { Solok } \\
\text { Ambah }\end{array}$ & - & - & - & - & 2 & 19 & - & - & 6 & 19 & 2 & 15 & 5 & 46 & 1 & 25 & 2 & 40 & - & - & 1 & 20 & 19 & 20 \\
\hline 5. & Paru & - & - & 1 & 33 & 4 & 36 & 3 & 75 & 6 & 19 & 2 & 15 & 1 & 9 & 1 & 25 & 1 & 20 & 1 & 50 & - & - & 20 & 21 \\
\hline & Jumlah & 5 & 100 & 3 & 100 & 11 & 100 & 4 & 100 & 32 & 100 & 13 & 100 & 11 & 100 & 4 & 100 & 5 & 100 & 2 & 100 & 5 & 100 & 95 & 100 \\
\hline
\end{tabular}

Sumber : Pengolahan Data Primer, 2017

Berdasarkan data yang diperoleh dari tabel 5 di atas, jenis pekerjaan pelaku mobilitas penduduk non-permanen pada daerah aksesibilitas rendah di Kecamatan
Sijunjung lebih banyak sebagai Pelajar/Mahasiswa berjumlah 27 orang $(35 \%)$ sedangkan yang sedikit sebagai Tukang Bangunan berjumlah 2 orang $(3 \%)$.

4. Tingkat Pendidikan Terakhir

Tabel 5. Deskripsi Frekuensi Tingkat Pendidikan Terakhir Pelaku Mobilitas Penduduk Non-Permanen Pada Daerah Aksesibilitas Rendah di Kecamatan Sijunjung

\begin{tabular}{|c|c|c|c|c|c|c|c|c|c|c|c|c|c|}
\hline \multirow{3}{*}{ No. } & \multirow{3}{*}{ Daerah Asal } & \multicolumn{10}{|c|}{ Pendidikan Terakhir } & \multirow{2}{*}{\multicolumn{2}{|c|}{ Jumlah }} \\
\hline & & \multicolumn{2}{|c|}{ Tamat SD } & \multicolumn{2}{|c|}{ Tamat SMP } & \multicolumn{2}{|c|}{ Tamat SMA } & \multicolumn{2}{|c|}{ Tamat PT } & \multicolumn{2}{|c|}{$\begin{array}{l}\text { Sedang } \\
\text { Sekolah }\end{array}$} & & \\
\hline & & $f$ & $\%$ & $\mathrm{~F}$ & $\%$ & $\mathrm{f}$ & $\%$ & $\bar{F}$ & $\%$ & $\mathrm{f}$ & $\%$ & f & $\%$ \\
\hline 1. & Silokek & 4 & 25 & 1 & 5 & 2 & 12 & 1 & 12,5 & 3 & 9 & 11 & 12 \\
\hline 2. & Durian Gadang & 2 & 13 & 5 & 23 & 2 & 12 & 1 & 12,5 & 10 & 31 & 20 & 21 \\
\hline 3. & Aie Angek & 4 & 25 & 8 & 36 & 5 & 29 & 1 & 12,5 & 7 & 22 & 25 & 26 \\
\hline 4. & Solok Ambah & 5 & 31 & 4 & 18 & 3 & 18 & 1 & 12,5 & 6 & 19 & 19 & 20 \\
\hline 5. & Paru & 1 & 6 & 4 & 18 & 5 & 29 & 4 & 50 & 6 & 19 & 20 & 21 \\
\hline & Jumlah & 16 & 100 & 22 & 100 & 17 & 100 & 8 & 100 & 32 & 100 & 95 & 100 \\
\hline
\end{tabular}

Sumber : Pengolahan Data Primer, 2017

Berdasarkan data yang diperoleh dari tabel 6 di atas, pendidikan terakhir pelaku mobilitas penduduk non-permanen pada daerah aksesibilitas rendah di Kecamatan
Sijunjung lebih banyak yang tamat SMP berjumlah 22 orang (23\%) sedangkan yang sedikit tamat Perguruan Tinggi berjumlah 8 orang $(10 \%)$. 


\section{Arah Pelaku Mobilitas}

1. Melewati Batas Kecamatan

Tabel 6. Distribusi Frekuensi Arah Pelaku Mobilitas Penduduk Non-

Permanen Pada Daerah Aksesibilitas Rendah di Kecamatan Sijunjung

Melewati Batas Kecamatan Regional Kabupaten Sijunjung

\begin{tabular}{|c|c|c|c|c|c|c|c|c|c|c|c|c|c|c|c|c|c|}
\hline \multirow{3}{*}{ No. } & \multirow{3}{*}{ Daerah Asal } & \multicolumn{14}{|c|}{$\begin{array}{c}\text { Arah Pelaku Melewati Batas Kecamatan } \\
\text { Regional Kabupaten Sijunjung }\end{array}$} & \multirow{2}{*}{\multicolumn{2}{|c|}{ Jumlah }} \\
\hline & & \multicolumn{2}{|c|}{$\begin{array}{r}\text { Sumpur } \\
\text { Kudus } \\
\end{array}$} & \multicolumn{2}{|c|}{ IV Nagari } & \multicolumn{2}{|c|}{ Kamang } & \multicolumn{2}{|c|}{$\begin{array}{l}\text { Tanjung } \\
\text { Gadang } \\
\end{array}$} & \multicolumn{2}{|c|}{ Kupitan } & \multicolumn{2}{|c|}{ Koto VII } & \multicolumn{2}{|c|}{$\begin{array}{l}\text { Lubuk } \\
\text { Tarok }\end{array}$} & & \\
\hline & & $\bar{F}$ & $\%$ & $\mathrm{f}$ & $\%$ & $\mathrm{~F}$ & $\%$ & $\mathrm{f}$ & $\%$ & $\mathrm{f}$ & $\%$ & $\mathrm{f}$ & $\%$ & $\mathrm{f}$ & $\%$ & $\mathrm{f}$ & $\%$ \\
\hline 1. & Silokek & 1 & 25 & 3 & 17 & - & - & - & - & 1 & 20 & 2 & 29 & - & - & 7 & 14 \\
\hline 2. & Durian Gadang & 3 & 75 & 3 & 17 & - & - & - & - & 1 & 20 & 2 & 29 & 1 & 100 & 10 & 20 \\
\hline 3. & Aie Angek & - & - & 7 & 39 & - & - & 3 & 25 & 1 & 20 & 1 & 13 & - & - & 12 & 25 \\
\hline 4. & Solok Ambah & - & - & 4 & 22 & 1 & 50 & 5 & 42 & 2 & 40 & 2 & 29 & - & - & 14 & 29 \\
\hline 5. & Paru & - & - & 1 & 5 & 1 & 50 & 4 & 33 & - & - & - & - & - & - & 6 & 12 \\
\hline & Jumlah & 4 & 100 & 18 & 100 & 2 & 100 & 12 & 100 & 5 & 100 & 7 & 100 & 1 & 100 & 49 & 100 \\
\hline
\end{tabular}

Sumber : Pengolahan Data Primer, 2017

Berdasarkan data yang banyak ke Kecamatan IV Nagari diperoleh dari tabel $8 \mathrm{di}$ atas, arah berjumlah 12 orang (32\%) pelaku mobilitas penduduk non- sedangkan yang sedikit ke permanen pada daerah aksesibilitas Kecamatan Lubuk Tarok berjumlah rendah di Kecamatan Sijunjung 1 orang (3\%). Yang dapat dilihat melewati batas kecamatan lebih pada gambar 2 di bawah ini :

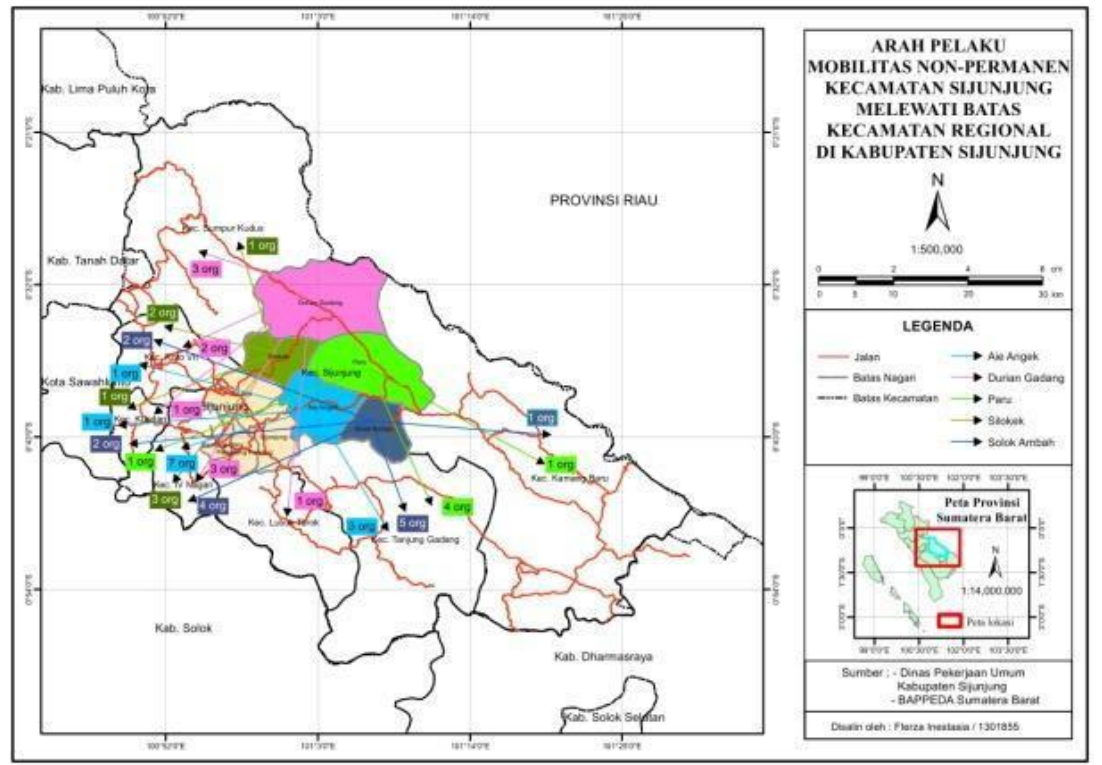

Gambar 2. Peta Arah Pelaku Melewati Batas Kecamatan

2. Melewati Batas Kabupaten

Tabel 7. Distribusi Frekuensi Arah Pelaku Mobilitas Penduduk NonPermanen Pada Daerah Aksesibilitas Rendah di Kecamatan Sijunjung Melewati Batas Kabupaten Regional Provinsi Sumatera Barat 


\begin{tabular}{|c|c|c|c|c|c|c|c|c|c|c|c|c|c|c|c|c|c|c|c|c|c|}
\hline \multirow{3}{*}{ No. } & \multirow{3}{*}{$\begin{array}{c}\text { Daerah } \\
\text { Asal }\end{array}$} & \multicolumn{18}{|c|}{$\begin{array}{c}\text { Arah Pelaku Melewati Batas Kabupaten } \\
\text { Regional Provinsi Sumatera Barat }\end{array}$} & \multirow{2}{*}{\multicolumn{2}{|c|}{ Jumlah }} \\
\hline & & \multicolumn{2}{|c|}{$\begin{array}{l}\text { Tanah } \\
\text { Datar }\end{array}$} & \multicolumn{2}{|c|}{ Sawahlunto } & \multicolumn{2}{|c|}{$\begin{array}{l}\text { Padang } \\
\end{array}$} & \multicolumn{2}{|c|}{ Kota Solok } & \multicolumn{2}{|c|}{$\begin{array}{r}\text { Solok } \\
\text { Selatan }\end{array}$} & \multicolumn{2}{|c|}{ Dhamasraya } & \multicolumn{2}{|c|}{ Bukittinggi } & \multicolumn{2}{|c|}{$\begin{array}{r}\text { Padang } \\
\text { Panjang }\end{array}$} & \multicolumn{2}{|c|}{$\begin{array}{c}\text { Kota } \\
\text { Pariaman }\end{array}$} & & \\
\hline & & $\mathrm{F}$ & $\%$ & $\mathrm{~F}$ & $\%$ & $\mathrm{f}$ & $\%$ & $\mathrm{f}$ & $\%$ & $\mathrm{f}$ & $\%$ & $\mathrm{~F}$ & $\%$ & $\mathrm{~F}$ & $\%$ & $\mathrm{f}$ & $\%$ & $\mathrm{f}$ & $\%$ & $\mathrm{f}$ & $\%$ \\
\hline 1. & Silokek & & - & 1 & 25 & 1 & 8 & - & & - & - & - & - & 2 & 29 & - & - & - & - & 2 & 6 \\
\hline 2. & $\begin{array}{l}\text { Durian } \\
\text { Gadang }\end{array}$ & - & - & 1 & 25 & 6 & 50 & 1 & 25 & - & - & - & - & 2 & 29 & - & - & - & - & 10 & 29 \\
\hline 3. & Aie Angek & - & - & - & - & 3 & 25 & 1 & 25 & - & - & 1 & 25 & 2 & 29 & - & - & 1 & 100 & 9 & 26 \\
\hline 4. & $\begin{array}{c}\text { Solok } \\
\text { Ambah }\end{array}$ & - & - & - & - & - & - & - & - & - & - & 2 & 50 & - & - & 1 & 50 & - & - & 3 & 8 \\
\hline 5. & Paru & 1 & 100 & 2 & 50 & 2 & 17 & 2 & 50 & 1 & 100 & 1 & 25 & 1 & 13 & 1 & 50 & - & - & 11 & 31 \\
\hline & Jumlah & 1 & 100 & 4 & 100 & 12 & 100 & 4 & 100 & 1 & 100 & 4 & 100 & 7 & 100 & 2 & 100 & 1 & 100 & 35 & 100 \\
\hline
\end{tabular}

Sumber : Pengolahan Data Primer, 2017

Berdasarkan data yang diperoleh dari tabel 9 di atas, arah pelaku mobilitas non-permanen pada daerah aksesibilitas rendah di Kecamatan Sijunjung melewati batas kabupaten regional Provinsi
Sumatera Barat lebih banyak ke Kota Padang berjumlah 11 orang (37\%), sedangkan yang sedikit ke Kabupaten Solok Selatan berjumlah 1 orang (3\%). Yang dapat dilihat pada gambar 3 di bawah ini :

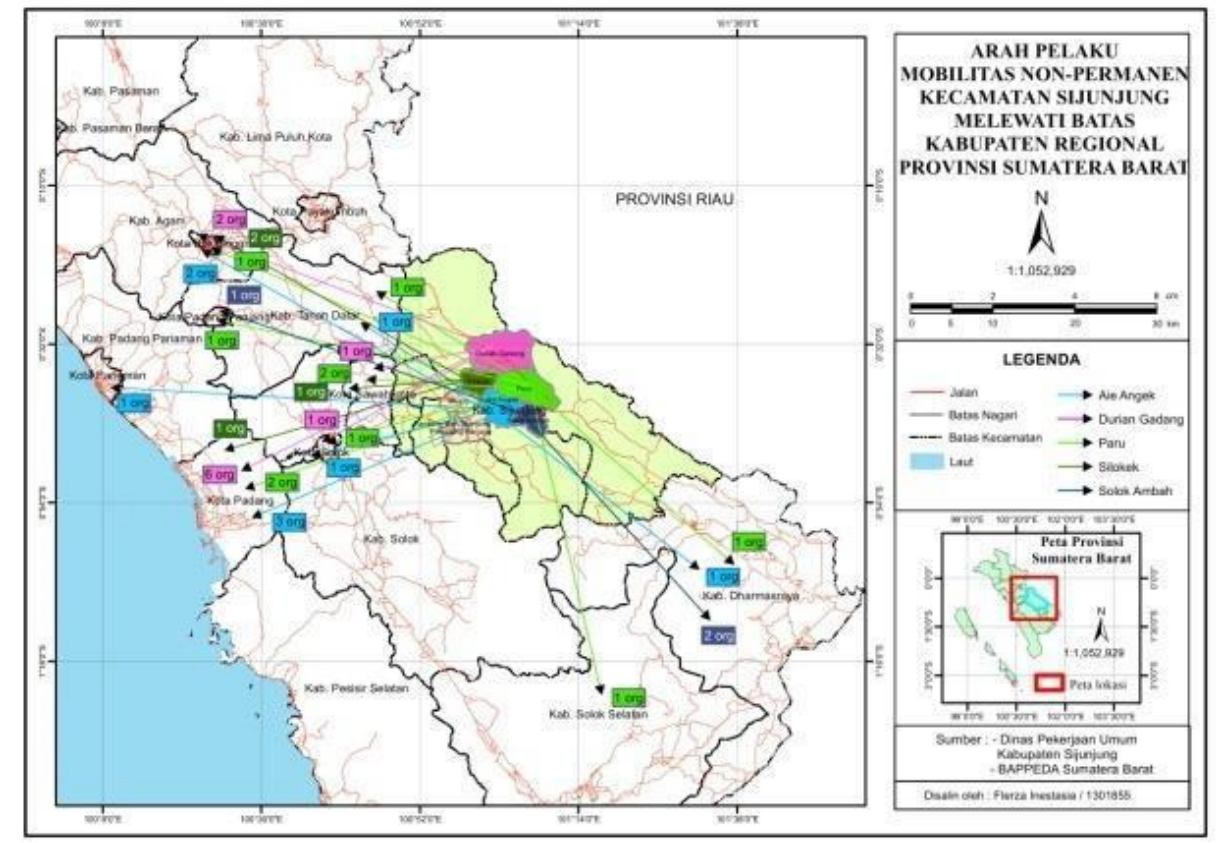

Gambar 3 : Peta Arah Pelaku Mobilitas Melewati Batas Kabupaten

3. Melewati Batas Provinsi

Tabel 8. Distribusi Frekuensi Arah Pelaku Mobilitas Penduduk NonPermanen Pada Daerah Aksesibilitas Rendah di Kecamatan Sijunjung Melewati Batas Provinsi Regional Indonesia 


\begin{tabular}{|c|c|c|c|c|c|c|c|c|c|c|c|c|c|c|c|}
\hline \multirow{3}{*}{ No. } & \multirow{3}{*}{$\begin{array}{c}\text { Daerah } \\
\text { Asal }\end{array}$} & \multicolumn{12}{|c|}{ Arah Pelaku Melewati Batas Provinsi Regional Indonesia } & \multirow{2}{*}{\multicolumn{2}{|c|}{ Jumlah }} \\
\hline & & \multicolumn{2}{|c|}{ Riau } & \multicolumn{2}{|c|}{ Bengkulu } & \multicolumn{2}{|c|}{ Batam } & \multicolumn{2}{|c|}{ Bogor } & \multicolumn{2}{|c|}{ Medan } & \multicolumn{2}{|c|}{ Palembang } & & \\
\hline & & $\mathrm{f}$ & $\%$ & $\mathrm{f}$ & $\%$ & $\mathrm{f}$ & $\%$ & $\mathrm{f}$ & $\%$ & $\mathrm{f}$ & $\%$ & $\mathrm{f}$ & $\%$ & $\mathrm{f}$ & $\%$ \\
\hline 1. & Silokek & 1 & 20 & - & - & 1 & 100 & - & - & - & - & - & - & 2 & 18 \\
\hline 2. & $\begin{array}{c}\text { Durian } \\
\text { Gadang }\end{array}$ & - & - & - & - & - & - & - & - & - & - & - & - & - & - \\
\hline 3. & $\begin{array}{c}\text { Aie } \\
\text { Angek }\end{array}$ & 2 & 40 & - & - & - & - & - & - & 1 & 100 & 1 & 100 & 4 & 36 \\
\hline 4. & $\begin{array}{c}\text { Solok } \\
\text { Ambah }\end{array}$ & 1 & 20 & 1 & 100 & - & - & - & - & - & - & - & - & 2 & 18 \\
\hline 5. & $\begin{array}{l}\text { Paru } \\
\end{array}$ & 1 & 20 & - & - & - & - & 2 & 100 & - & - & - & - & 3 & 28 \\
\hline & Jumlah & 5 & 100 & 1 & 100 & 1 & 100 & 2 & 100 & 1 & 100 & 1 & 100 & 11 & 100 \\
\hline
\end{tabular}

Sumber : Pengolahan Data Primer, 2017

Berdasarkan data yang Indonesia yang paling banyak ke diperoleh dari tabel $10 \mathrm{di}$ atas, arah Provinsi Riau berjumlah 4 orang pelaku mobilitas penduduk non- (40\%) sedangkan yang sedikitke permanen pada daerah aksesibilitas Provinsi Bengkulu, Batam, Kota rendah di Kecamatan Sijunjung Medan dan Kota Palembang masingmelewati batas provinsi regional masing berjumlah 1 orang (10\%).

\section{Alasan Pelaku Mobilitas}

Tabel 9. Deskripsi Frekuensi Alasan Pelaku Mobilitas Penduduk Non-

Permanen Pada Daerah Aksesibilitas Rendah di Kecamatan Sijunjung

\begin{tabular}{|c|c|c|c|c|c|c|c|}
\hline \multirow{2}{*}{ No. } & \multirow{2}{*}{ Daerah Asal } & \multicolumn{4}{|c|}{ Alasan } & \multicolumn{2}{|}{} \\
\cline { 3 - 6 } & & \multicolumn{2}{|c|}{ Pekerjaan } & \multicolumn{2}{|c|}{ Pendidikan } & \multicolumn{2}{|c|}{ Jumlah } \\
\cline { 3 - 8 } & f & $\%$ & $\mathrm{f}$ & $\%$ & $\mathrm{f}$ & $\%$ \\
\hline 1. & Silokek & 8 & 13 & 3 & 9 & 11 & 12 \\
\hline 2. & Durian Gadang & 10 & 16 & 10 & 31 & 20 & 21 \\
\hline 3. & Aie Angek & 18 & 28 & 7 & 22 & 25 & 26 \\
\hline 4. & Solok Ambah & 13 & 21 & 6 & 19 & 19 & 20 \\
\hline 5. & Paru & 14 & 22 & 6 & 19 & 20 & 21 \\
\hline & Jumlah & 63 & 100 & 32 & 100 & 95 & 100 \\
\hline
\end{tabular}

Sumber : Pengolahan Data Primer, 2017

Berdasarkan data yang rendah di Kecamatan Sijunjung diperoleh dari tabel $11 \mathrm{di}$ atas, alasan minimal melewati batas kecamatan pelaku mobilitas penduduk non- lebih banyak beralasan karena permanen pada daerah aksesibilitas pekerjaan berjumlah 51 orang $(65 \%)$.

\section{Pola Mobilitas Penduduk}

1. Pelaku Mobilitas Berdasarkan Status Dalam Keluarga

Tabel 10. Distribusi Frekuensi Pelaku Mobilitas Penduduk Non-

Permanen Pada Daerah Aksesibilitas Rendah di Kecamatan Sijunjung Berdasarkan Status Keluarga 


\begin{tabular}{|c|c|c|c|c|c|c|c|c|c|}
\hline \multirow{2}{*}{ No. } & Status Keluarga & \multicolumn{2}{|c|}{ Ayah } & \multicolumn{2}{|c|}{ Ibu } & \multicolumn{2}{c|}{ Anak } & \multicolumn{2}{c|}{ Jumlah } \\
\hline & $\begin{array}{c}\text { Batas } \\
\text { Administrasi }\end{array}$ & $\mathrm{f}$ & $\%$ & $\mathrm{~F}$ & $\%$ & $\mathrm{f}$ & $\%$ & $\mathrm{f}$ & $\%$ \\
\hline 1. & $\begin{array}{c}\text { Melewati Batas } \\
\text { Kecamatan }\end{array}$ & 21 & 62 & 5 & 62,5 & 23 & 43 & 49 & 51 \\
\hline 2. & $\begin{array}{c}\text { Melewati Batas } \\
\text { Kabupaten }\end{array}$ & 10 & 29 & 2 & 25 & 23 & 43 & 35 & 37 \\
\hline 3. & $\begin{array}{c}\text { Melewati Batas } \\
\text { Provinsi }\end{array}$ & 3 & 9 & 1 & 12,5 & 7 & 14 & 11 & 12 \\
\hline & Jumlah & 34 & 100 & 8 & 100 & 53 & 100 & 95 & 100 \\
\hline
\end{tabular}

Sumber : Pengolahan Data Primer, 2017

Dari tabel 29 dapat dilihat bahwa pelaku mobilitas penduduk non-permanen pada daerah aksesibilitas rendah di Kecamatan

Sijunjung berdasarkan status keluarga melewati batas administrasi, yang melewati batas kecamatan lebih banyak yang berstatus sebagai anak berjumlah 23 orang (43\%), melewati batas kabupaten lebih banyak yang berstatus anak berjumlah 23 orang (43\%), dan melewati batas provinsi lebih banyak yang berstatus anak berjumlah 7 orang (14\%).

2. Pelaku Mobilitas Berdasarkan Jenis Kelamin

Tabel 11. Distribusi Frekuensi Pelaku Mobilitas Penduduk NonPermanen Pada Daerah Aksesibilitas Rendah di Kecamatan Sijunjung Berdasarkan Jenis Kelamin

\begin{tabular}{|c|c|c|c|c|c|c|c|}
\hline \multirow{2}{*}{ No. } & Jenis Kelamin & \multicolumn{2}{|c|}{ Laki-laki } & \multicolumn{2}{|c|}{ Perempuan } & \multicolumn{2}{|c|}{ Jumlah } \\
\cline { 3 - 8 } & $\begin{array}{c}\text { Batas } \\
\text { Administrasi }\end{array}$ & $\mathrm{f}$ & $\%$ & $\mathrm{f}$ & $\%$ & $\mathrm{f}$ & $\%$ \\
\hline 1. & $\begin{array}{c}\text { Melewati Batas } \\
\text { Kecamatan }\end{array}$ & 29 & 50 & 20 & 54 & 49 & 51 \\
\hline 2. & $\begin{array}{c}\text { Melewati Batas } \\
\text { Kabupaten }\end{array}$ & 20 & 34 & 15 & 41 & 35 & 37 \\
\hline 3. & $\begin{array}{c}\text { Melewati Batas } \\
\text { Provinsi }\end{array}$ & 9 & 16 & 2 & 5 & 11 & 12 \\
\hline & Jumlah & 58 & 100 & 37 & 100 & 95 & 100 \\
\hline
\end{tabular}

Sumber : Pengolahan Data Primer, 2017

Dari tabel 30 dapat dilihat bahwa pelaku mobilitas penduduk non-permanen pada daerah aksesibilitas rendah di Kecamatan Sijunjung berdasarkan jenis kelamin melewati batas administrasi, yang melewati batas kecamatan lebih banyak berjenis kelamin laki-laki melewati batas kecamatan berjumlah 29 orang $(50 \%)$ sedangkan berjenis kelamin Perempuan melewati batas kecamatan berjumlah 20 orang $(54 \%)$.

3. Pelaku Mobilitas Berdasarkan Umur

Tabel 12. Distribusi Frekuensi Pelaku Mobilitas Penduduk NonPermanen Pada Daerah Aksesibilitas Rendah di Kecamatan Sijunjung Berdasarkan Umur 


\begin{tabular}{|c|c|c|c|c|c|c|c|c|c|c|c|c|c|}
\hline \multirow[t]{2}{*}{ No. } & \multirow[t]{2}{*}{ Umur } & \multicolumn{2}{|c|}{$\begin{array}{c}13-20 \\
\text { Tahun }\end{array}$} & \multicolumn{2}{|c|}{$\begin{array}{c}21-28 \\
\text { Tahun }\end{array}$} & \multicolumn{2}{|c|}{$\begin{array}{c}29-36 \\
\text { Tahun }\end{array}$} & \multicolumn{2}{|c|}{$\begin{array}{r}37-44 \\
\text { Tahun }\end{array}$} & \multicolumn{2}{|c|}{$\begin{array}{l}45-51 \\
\text { Tahun }\end{array}$} & \multicolumn{2}{|c|}{ Jumlah } \\
\hline & & $\bar{F}$ & $\%$ & $f$ & $\%$ & $\mathrm{f}$ & $\%$ & $\mathrm{f}$ & $\%$ & $\mathrm{f}$ & $\%$ & f & $\%$ \\
\hline 1. & $\begin{array}{l}\text { Melewati Batas } \\
\text { Kecamatan }\end{array}$ & 16 & 61 & 8 & 29 & 11 & 61 & 8 & 73 & 6 & 50 & 49 & 51 \\
\hline 2. & $\begin{array}{l}\text { Melewati Batas } \\
\text { Kabupaten }\end{array}$ & 9 & 35 & 14 & 50 & 7 & 39 & 1 & 9 & 4 & 33 & 35 & 37 \\
\hline 3. & $\begin{array}{c}\text { Melewati Batas } \\
\text { Provinsi }\end{array}$ & 1 & 4 & 6 & 21 & - & - & 2 & 18 & 2 & 17 & 11 & 12 \\
\hline & Jumlah & 26 & 100 & 28 & 100 & 18 & 100 & 11 & 100 & 12 & 100 & 95 & 100 \\
\hline
\end{tabular}

Sumber : Pengolahan Data Primer, 2017

Dari tabel 31 dapat dilihat bahwa umur pelaku mobilitas nonpermanen pada daerah aksesibilitas rendah di Kecamatan Sijunjung lebih banyak penduduk dengan umur 21 28 tahun melewati batas kabupaten berjumlah 14 orang (50\%). Umur pelaku mobilitas penduduk nonpermanen pada daerah aksesibilitas rendah di Kecamatan Sijunjung dengan umur 13 - 20 tahun lebih banyak melewati batas kecamatan berjumlah 16 orang (61\%), umur 21 - 28 tahun lebih banyak melewati batas kabupaten berjumlah 14 orang (50\%), umur 29 - 36 tahun lebih banyak melewati kecamatan berjumlah 11 orang (61\%), umur 37 - $\quad 44$ tahun lebih banyak melewati kecamatan berjumlah 8 orang (73\%), dan umur 45 - 51 tahun lebih banyak melewati batas kecamatan berjumlah 6 orang $(50 \%)$.

4. Pelaku Mobilitas Berdasarkan Jenis Pekerjaan

Tabel 13. Distribusi Frekuensi Pelaku Mobilitas Penduduk NonPermanen Pada Daerah Aksesibilitas Rendah di Kecamatan Sijunjung Berdasarkan Jenis Pekerjaan

\begin{tabular}{|c|c|c|c|c|c|c|c|c|c|c|c|c|c|c|c|c|c|c|c|c|c|c|c|c|c|}
\hline \multirow[t]{2}{*}{ No. } & \multirow{2}{*}{$\begin{array}{l}\text { Jenis } \\
\text { Batas } \\
\text { Administrasi }\end{array}$} & \multicolumn{2}{|c|}{$\begin{array}{l}\text { Penambang } \\
\text { Emas }\end{array}$} & \multicolumn{2}{|c|}{$\begin{array}{l}\text { Pekerja } \\
\text { Bengkel }\end{array}$} & \multicolumn{2}{|c|}{ Honorer } & \multicolumn{2}{|c|}{$\begin{array}{l}\text { Pegawai } \\
\text { Negeri }\end{array}$} & \multicolumn{2}{|c|}{$\begin{array}{c}\text { Pelajar/ } \\
\text { Mahasiswa }\end{array}$} & \multicolumn{2}{|c|}{ Pedagang } & \multicolumn{2}{|c|}{$\begin{array}{l}\text { Petani/ } \\
\text { Pekebun }\end{array}$} & \multicolumn{2}{|c|}{ Supir } & \multicolumn{2}{|c|}{ Wiraswasta } & \multicolumn{2}{|c|}{$\begin{array}{c}\text { Tukang } \\
\text { Bangunan }\end{array}$} & \multicolumn{2}{|c|}{$\begin{array}{r}\text { Karyawan } \\
\text { Swasta }\end{array}$} & \multicolumn{2}{|c|}{ Jumlah } \\
\hline & & $\mathrm{f}$ & $\%$ & $\mathrm{f}$ & $\%$ & F & $\%$ & $\mathrm{f}$ & $\%$ & $\mathrm{f}$ & $\%$ & $\mathrm{f}$ & $\%$ & $\mathrm{f}$ & $\%$ & $\mathrm{f}$ & $\%$ & $\mathrm{f}$ & $\%$ & $\mathrm{f}$ & $\%$ & $\mathrm{f}$ & $\%$ & $\mathrm{f}$ & $\%$ \\
\hline 1. & $\begin{array}{c}\text { Melewati } \\
\text { Batas } \\
\text { Kecamatan }\end{array}$ & 5 & 100 & 1 & 33 & 5 & 45 & 1 & 25 & 16 & 50 & 7 & 54 & 9 & 82 & 1 & 25 & - & & 2 & 100 & 2 & 40 & 49 & 51 \\
\hline 2. & $\begin{array}{c}\text { Melewati } \\
\text { Batas } \\
\text { Kabupaten }\end{array}$ & - & - & 2 & 67 & 6 & 55 & 2 & 50 & 14 & 44 & 5 & 38 & 2 & 18 & 1 & 25 & 3 & 60 & - & - & - & - & 35 & 37 \\
\hline 3. & $\begin{array}{c}\text { Melewati } \\
\text { Batas } \\
\text { Provinsi } \\
\end{array}$ & - & & - & - & - & - & 1 & 25 & 2 & 6 & 1 & 8 & & - & 2 & 50 & 2 & 40 & & & 3 & 60 & 11 & 12 \\
\hline & Jumlah & 5 & 100 & 3 & 100 & 11 & 100 & 4 & 100 & 32 & 100 & 13 & 100 & 11 & 100 & 4 & 100 & 5 & 100 & 2 & 100 & 5 & 100 & 95 & 100 \\
\hline
\end{tabular}

Sumber : Pengolahan Data Primer, 2017

Dari tabel 32 dapat dilihat pelaku mobilitas penduduk nonpermanen pada daerah aksesibilitas rendah di Kecamatan Sijunjung berdasarkan jenis pekerjaan lebih banyak sebagai Pelajar/Mahasiswa melewati batas kecamatan berjumlah 16 orang $(50 \%)$. Jenis pekerjaan pelaku mobilitas penduduk nonpermanen pada daerah aksesibilitas rendah di Kecamatan Sijunjung sebagai penambang emas lebih 
banyak melewati batas kecamatan berjumlah 5 orang (100\%), sebagai pekerja bengkel lebih banyak melewati batas kabupaten berjumlah 2 orang (67\%), sebagai honorer lebih banyak melewati batas kabupaten berjumlah 6 orang (55\%), sebagai pegawai negeri lebih banyak melewati batas kabupaten berjumlah 2 orang (50\%), sebagai pelajar/mahasiswa lebih banyak melewati batas kecamatan berjumlah 16 orang $(50 \%)$, sebagai pedagang lebih banyak melewati batas kecamatan berjumlah 7 orang (54\%), sebagai petani/pekebun lebih banyak melewati batas kecamatan berjumlah 9 orang (82\%), sebagai supir lebih banyak melewati batas provinsi berjumlah 2 orang (50\%), sebagai wiraswasta lebih banyak melewati batas kabupaten berjumlah 3 orang (60\%), sebagai tukang bangunan lebih banyak melewati batas kecamatan berjumlah 2 orang (50\%), dan sebagai karyawan swasta lebih banyak melewati batas provinsi berjumlah 3 orang (60\%).

5. Pelaku Mobilitas Berdasarkan Pendidikan Terakhir

Tabel 14. Distribusi Frekuensi Pelaku Mobilitas Penduduk NonPermanen Pada Daerah Aksesibilitas Rendah di Kecamatan Sijunjung Berdasarkan Pendidikan Terakhir

\begin{tabular}{|c|c|c|c|c|c|c|c|c|c|c|c|c|c|}
\hline \multirow[t]{2}{*}{ No. } & \multirow{2}{*}{$\begin{array}{l}\text { Batas } \\
\text { Administrasi }\end{array}$} & \multicolumn{2}{|c|}{ Tamat SD } & \multicolumn{2}{|c|}{ Tamat SMP } & \multicolumn{2}{|c|}{ Tamat SMA } & \multicolumn{2}{|c|}{ Tamat PT } & \multicolumn{2}{|c|}{$\begin{array}{l}\text { Sedang } \\
\text { Sekolah }\end{array}$} & \multicolumn{2}{|c|}{ Jumlah } \\
\hline & & $\mathrm{f}$ & $\%$ & $\mathrm{f}$ & $\%$ & $\mathrm{f}$ & $\%$ & $\mathrm{f}$ & $\%$ & $\mathrm{f}$ & $\%$ & $\mathrm{f}$ & $\%$ \\
\hline 1. & $\begin{array}{c}\text { Melewati Batas } \\
\text { Kecamatan }\end{array}$ & 11 & 69 & 12 & 55 & 5 & 29 & 5 & 62,5 & 16 & 50 & 49 & 51 \\
\hline 2. & $\begin{array}{l}\text { Melewati Batas } \\
\text { Kabupaten }\end{array}$ & 5 & 31 & 4 & 18 & 10 & 59 & 2 & 25 & 14 & 44 & 35 & 37 \\
\hline 3. & $\begin{array}{c}\text { Melewati Batas } \\
\text { Provinsi }\end{array}$ & - & & 6 & 27 & 2 & 12 & 1 & 12,5 & 2 & 6 & 11 & 12 \\
\hline & Jumlah & 16 & 100 & 22 & 100 & 17 & 100 & 8 & 100 & 32 & 100 & 95 & 100 \\
\hline
\end{tabular}

Sumber : Pengolahan Data Primer, 2017

Dari tabel 33 dapat dilihat bahwa pendidikan terakhir pelaku mobilitas penduduk non-

$\begin{array}{lrr}\text { permanen } & \text { pada } & \text { daerah } \\ \text { aksesibilitas } & \text { rendah } & \text { di }\end{array}$ Kecamatan Sijunjung lebih banyak yang tamat SMP

melewati batas kecamatan berjumlah 12 orang (55\%).

Pendidikan terakhir pelaku mobilitas penduduk nonpermanen pada daerah aksesibilitas rendah di Kecamatan Sijunjung tamat SD lebih banyak melewati batas kecamatan berjumlah 11 orang (69\%), tamat SMP lebih banyak melewati batas kecamatan berjumlah 12 orang (55\%), tamat SMA lebih banyak melewati batas kabupaten berjumlah 10 orang $(59 \%)$, tamat perguruan tinggi lebih banyak melewati batas kecamatan berjumlah 5 orang $(62,5 \%)$, dan yang masih bersekolah lebih banyak melewati batas kecamatan berjumlah 16 orang (50\%). 
6. Pola Mobilitas Penduduk

Tabel 15. Deskripsi Frekuensi Pola Mobilitas Penduduk

Non-Permanen Pada Daerah Aksesibilitas Rendah di

Kecamatan Sijunjung Dengan Status Dalam Keluarga

\begin{tabular}{|c|c|c|c|c|c|c|c|}
\hline \multirow{2}{*}{ No. } & \multirow{3}{*}{$\begin{array}{c}\text { Status Dalam } \\
\text { Keluarga }\end{array}$} & \multicolumn{4}{|c|}{ Pola Mobilitas Penduduk Non-Permanen } & \multicolumn{2}{c|}{ Jumlah } \\
\cline { 3 - 8 } & & \multicolumn{2}{|c|}{ Ulang-alik } & \multicolumn{2}{c|}{ Menginap } & \multicolumn{2}{c|}{} \\
\cline { 3 - 8 } & & $\mathrm{f}$ & $\%$ & $\mathrm{~F}$ & 10 & $\mathrm{f}$ & $\%$ \\
\hline 1. & Ayah & 23 & 67 & 10 & 4 & 33 & 35 \\
\hline 2. & Ibu & 6 & 18 & 2 & 80 & 54 & 57 \\
\hline 3. & Anak & 5 & 15 & 49 & 100 & 95 & 100 \\
\hline & Jumlah & 34 & 100 & 61 & & \\
\hline
\end{tabular}

Sumber : Pengolahan DataPrimer, 2017

Dari tabel 15 di atas dapat dilihat bahwa pola mobilitas dengan status dalam keluarga pelaku mobilitas penduduk non-permanen

pada aksesibilitas rendah di Kecamatan Sijunjung, pola ulang-

Dari hasil penelitian dilapangan, maka pembahasan dari pola mobilitas non-permanen yaitu:

1. Karakteristik Pelaku Mobilitas

Karakteristik pelaku mobilitas penduduk non-permanen pada daerah aksesibilitas rendah di Kecamatan Sijunjung minimal melewati batas kecamatan berdominan adalah lakilaki, dengan lebih banyak berumur $18-28$ tahun. Pendidikan terakhir pelaku mobilitas penduduk nonpermanen pada daerah aksesibilitas rendah di Kecamatan Sijunjung lebih banyak yang tamat SMP. Pekerjaan pelaku mobilitas penduduk nonpermanen lebih banyak sebagai pelajar atau mahasiswa dan tingkat pendapatan pelaku mobilitas penduduk non-permanen lebih banyak tidak memiliki pendapatan dikarenakan banyak yang masih bersekolah. alik lebih banyak berstatus sebagai ayah berjumlah 23 orang (67\%) dan pola menginap lebih banyak berstatus sebagai anak berjumlah 49 orang $(80 \%)$.

Dari beberapa karakteristik tersebut sesuai dengan teori tentang karakteristik migran menurut Ravenstein dalam (Asih, 2015) yang di temukan peneliti : Pada umumnya penduduk melakukan mobilitas berpindah hanya pada suatu jarak yang tidak jauh dan sebagian besar tujuan penduduk mobilitas adalah daerah yang mayoritas pusat pendidikan dan perdagangan. Serta

sesuai beberapa penelitian (UGM;1986, Hidayat;1991, Romdiati dan Noveria;2008 dalam Mincie H. Ubro dkk, 2015) salah satunya adalah berpendidikan rendah (SD atau SMP) dan didominasi kaum laki-laki. Serta dari struktur umur mereka merupakan kelompok umur produktif (antara 15-44 tahun).

2. Arah Mobilitas

Arah pelaku mobilitas penduduk non-permanen pada daerah aksesiblitas rendah di Kecamatan 
Sijunjung lebih banyak melewati batas kecamatan yang dominan ke Kecamatan IV Nagari, melewati batas kabupaten dominan ke Kota Padang, dan melewati batas provinsi dominan ke Provinsi Riau.

Hal ini sejalan sesuai dengan pendapat Mantra (2009), bahwa faktor dari daerah asal yang disebut faktor pendorong seperti : lapangan kerja terbatas, keamanan terganggu, kurangnya sarana pendidikan. Faktor penarik seperti : tersedianya lapangan kerja, upah tinggi,

tersedianya sarana pendidikan, kesehatan dan hiburan. Faktor yang terletak diantara daerah asal dan

daerah tujuan yang disebut penghalang seperti : jarak, jenis transportasi, dan biaya transportasi. Maka dari hal tersebut dapat dilihat jika jarak yang jauh dan sulitnya transportasi akan menghambat mobilitas penduduk itu sendiri.

3. Alasan Melakukan Mobilitas

Alasanpelakumobilitas

penduduk non-permanen pada daerah aksesibilitas rendah di Kecamatan Sijunjung minimal melewati batas kecamatan lebih dominan karena pekerjaan.

Menurut beberapa ahli, seperti : Lee (1966), Todaro (1979), Titus (1982) dalam (Mincie H. Ubro, dkk , 2015), berpendapat bahwa motivasi seseorang untuk pindah adalah motif ekonomi kesempatan kerja sesuai dengan keahlian mereka.

4. Pola Mobilitas Penduduk
Pola mobilitas penduduk nonpermanen pada daerah aksesibilitas rendah di Kecamatan Sijunjung adalah lebih banyak menginap dengan lebih banyak bersifat mingguan.

Keadaan ini sesuai dengan pendapat menurut Zelinsky dalam (Asih, 2011) secara umum diartikan sebagai perpindahan penduduk dari satu wilayah ke wilayah lain dengan tidak ada maksud untuk menetap di daerah tujuan dicirikan oleh perpindahan jangka pendek, berulang atau dilakukan secara teratur.

Menurut Ruslan H. Prawiro (1983) yang menyatakan mobilitas penduduk non-permanen adalah gerak penduduk yang dilakukan dari v satu wilayah ke wilayah lain dalam waktu kurang dari enam bulan terdiri dari pola mobilitas harian, mingguan, dan bulanan.

\section{Kesimpulan}

Dari 97 rumahtangga terdapat 74 rumahtangga dengan total 95 orang yang melakukan mobilitas non-permanen minimal melewati batas kecamatan dengan lebih banyak yang melakukan mobilitas tersebut berstatus anggota keluarga khususnya berstatus anak berjumlah 45 orang (58\%), dengan kesimpulan yaitu sebagai berikut :

1. Karakteristik pelaku mobilitas penduduk non-permanen pada daerah aksesibilitas rendah di Kecamatan Sijunjung dominan adalah laki-laki berjumlah 47 orang $(60 \%)$ dengan mendominasi 
umur $18-28$ tahun berjumlah 32 orang $(41 \%)$. Pelaku mobilitas lebih banyak yang tamat SMP berjumlah 22 orang (23\%).

Pekerjaan pelaku mobilitas penduduk non-permanen lebih banyak sebagai pelajar atau mahasiswa berjumlah 27 orang (35\%).

2. Arah pelaku mobilitas penduduk non-permanen pada daerah aksesiblitas rendah di Kecamatan

Sijunjung, melewati batas kecamatan berjumlah 38 orang (49\%).

3. Alasan pelaku mobilitas penduduk non-permanen pada daerah aksesibilitas rendah di kecamatan sijunjung terdiri dari pekerjaan berjumlah 51 orang $(65 \%)$.

4. Pola mobilitas penduduk nonpermanen pada daerah aksesibilitas rendah di Kecamatan Sijunjung adalah lebih banyak berjumlah menginap berjumlah 52 orang (67\%) dengan bersifat mingguan berjumlah 29 orang $(37 \%)$.

\section{Saran}

1. Bagi masyarakat yang umumnya melakukan mobilitas penduduk non-permanen adalah pelajar/mahasiswa agar dapat berpartisipasi dalam membangun Kecamatan Sijunjung khususnya pada daerah masing-masing.

2. Bagipemerintahkecamatan sijunjungdanpemerintah kabupaten sijunjung agar lebih memberikan peningkatkan sarana dan prasana dalam menunjang mobilitas masyarakat, terutama akses transportasi dan jalan yang terdapat pada daerah yang memiliki aksesibilitas rendah.

3. Dapat menjadi acuan bagi pemerintah untuk mengetahui mobilitas yang dilakukan masyarakat kecamatan sijunjung sehingga dapat mengambil keputusan dalam menentukan arah pembangunan masyarakat di masa mendatang.

\section{Daftar Pustaka}

Hardoko, R. (1987). Mobilitas Migrasi dan Urbanisasi. Bandung: Angkasa.

Mantra, I. B. (2009). Demografi Umum. Yogyakarta: Pustaka Pelajar. M, A. (2017, Mei 15).

Padangkita.com. Retrieved Juli 27, 2017, from http://padangkita.com/longsorribuan-warga-sijunjungterisolir/

Mincie H Ubro, R. K. (2015). Mobilitas Sirkuler di Indonesia. 3 - 11.

Prawiro, Ruslan H. (1983). Kependudukan Teori, Fakta, dan Masalah. Bandung: Penerbit Alumni.

Ramadhani, Asih (2011). Mobilitas Penduduk Non-Permanen Desa Simpang Karimio Kecamatan Batan XXIV Kabupaten Batang Hari Provinsi Jambi. Padang FIS UNP: Skripsi. 